\title{
City Size, Urban-Rural Income Gap and Environmental Pollution: Empirical Evidence from 283 Cities in China
}

\author{
Feng Wang ${ }^{1 *}$, Wei Chai ${ }^{1}$, Juan Liu ${ }^{1}$, Jing Ren${ }^{1}$, Jing Shan ${ }^{1}$, Zhiying Li ${ }^{2 * *}$ \\ ${ }^{1}$ School of Economics and Management, China University of Mining and Technology, \\ No. 1, College Rd., Tongshan Dist., Xuzhou 221116, Jiangsu Province, China \\ ${ }^{2}$ College of Foreign Studies, South China Agricultural University, No. 483, \\ Wushan Road, Guangzhou, 510642, Guangdong Province, China
}

Received: 8 October 2020

Accepted: 21 November 2020

\begin{abstract}
Using the balanced panel data of 283 cities at the level of municipality or above in China from 2014 to 2017, this study adopts the system generalized method of moments (SGMM) and panel threshold model to study the relationship among city size, urban-rural income gap and environmental pollution. The conclusions are as follows: (1) There is an inverted U-shaped relationship between city size and environmental pollution; (2) Urban-rural income gap can significantly aggravate environmental pollution; (3) Urban-rural income gap has a regulatory effect on the relationship between city size and environmental pollution. When the urban-rural income gap crosses the threshold, the intensity of environmental pollution caused by city size changes. Therefore, optimizing the city size and narrowing the urban-rural income gap will reduce urban environmental pollution.
\end{abstract}

Keywords: environmental pollution, city size, urban-rural income gap, SGMM

\section{Introduction}

Since the reform and opening up, China's urbanization has experienced rapid development from a weak base. The resident population in cities has increased from 172 million in 1978 to 848 million in 2019, and the urbanization rate has increased from $17.90 \%$ to $60.60 \%$. The rapid development of urbanization has brought about a great expansion in the size of cities.

*e-mail: fengwang@cumt.edu.cn

**e-mail: azureli@scau.edu.cn
In 2019, the number of cities at the level of municipality or above in China is 297, among which 20 cities have more than 4 million population at the end of the year, 42 cities of 2-4 million, and 99 cities of 1-2 million. The expansion of the city size has promoted rapid economic development, while it has also brought a series of social problems. Among them, environmental pollution is of the greatest concern. From the perspective of environmental pollution, China's economy has experienced rapid development for more than 40 years and has made great achievements. However, with the economic growth mode of high energy consumption and high pollution, environmental pollution is becoming increasingly 
serious. Under the current environmental background, studying the influencing factors of environmental pollution has important practical significance. „urban diseases" such as industrial pollution, road congestion, and housing shortages are common problems in the process of urbanization. Therefore, many scholars attribute environmental pollution to urban development and believe that controlling the scale of cities is the key to solving environmental pollution.

Another typical fact is that with the development of cities, the urban-rural income gap is also a major problem in China. The classic Environmental Kuznets Curve (EKC) considers the impact of per capita income on environmental pollution, but ignores the existence of income gap and its possible impact on environmental pollution. There are two mechanisms by which income gap affects environmental pollution: One is that environmental quality is a public good, groups with high income generally have higher requirements for environmental quality, while the environmental quality of the entire society is determined by the median voter; Second, because of the difference in consumption power, groups with high incomes can avoid pollution by transferring property, immigration, etc. China has regarded improving environmental quality and narrowing income gap as its social development goals. Therefore, in-depth exploration of the mechanism and effect of income gap on environmental pollution in China has important theoretical and practical significance. In addition, the widening of the income gap between urban and rural areas will cause more rural people migrate to cities, it will further expand the size of cities, and few scholars have conducted research on whether this will affect environmental pollution.

Therefore, it is worth figuring out what the relationship is between China's expansion of city size and the environmental pollution. Will the expansion of cities increase or reduce environmental pollution? What are the interaction mechanisms among city size, urban-rural income gap and environmental pollution? In-depth discussion of these issues will help to improve the quality of urban development, and offer insights for realization of urban sustainable development and the urbanization development of other developing countries. Therefore, this study uses data from 283 cities at the level of municipality or above in China from 2014 to 2017 to analyze the relationship among the environmental pollution, city size and urban-rural income gap which have important impacts on the process of urbanization.

Scholars have conducted extensive research on the relationship between city size, urban-rural income gap and environmental pollution. The research focuses on the following three aspects:

(1) City size and urban-rural income gap: Scholars have studied the relationship between city size and urban-rural income gap for a long time. For example, Alperovich [1] argues that the relationship between city size and income inequality is uncertain and can be changed when other conditions are added by constructing a general equilibrium model. David [2] considers the city size and income gap to be U-shaped. Based on a data set of 30 provincial-level regions in China over 1997-2015, Wang et al. [3] argue that increasing urbanization has a significant effect on mitigating urban-rural income disparity. However, most studies support the view that the city size has significantly widened the urban-rural income gap. For example, Baek and Gweisah [4] analyze US data from 1979 to 2007 and argue that city size can explain onequarter to one-third of the difference in hourly wages. Some scholars [5-10] analyze China's data to prove that city size has significantly widened the urban-rural income gap, as those migrating to urban cities are mostly people with excellent comprehensive quality and labor ability, which greatly increase urban productivity, thus further widening the urban-rural income gap.

(2) City size and environmental pollution: The impact of city size on environmental pollution has been studied by many scholars, but the conclusions are inconsistent. Li et al. [11] argue that in a certain period, the cities have the optimal scale. Hence, city size has different effects on environmental pollution. Some studies believe that the expansion of cities has a scale effect: Firstly, it can improve the utilization efficiency of public infrastructure, such as giving full play to the scale effect of public transport system thus reducing the generation of pollutants; Secondly, with the expansion of the city size, the investment in environmental governance will increase gradually and the pollution control technology will progress gradually, which will help improve the environmental quality and significantly reduce environmental pollution [12-17]. While other researches argue that the expansion of the city size will have congestion effects. Firstly, because of the concentration of industries and production activities, urban enterprises will increase the demand for energy, which will lead to an increase in energy consumption and pollution emissions. Secondly, under the congestion effect, the conflict between people and land, the shortage of infrastructure supply are prominent, which will lead to the decline of resource utilization efficiency and further deterioration of environmental pollution [18-27]. In addition, some scholars believe that the impact of city size on environmental pollution, which is affected by other factors, is not a fixed positive or negative effect. For example, Liu et al. [28] argue that there was a significantly inverted $\mathrm{N}$-shaped correlation between PM2.5 and city size, which supports the "Pollution Haven Hypothesis". With the expansion of the city size, the PM2.5 concentration in the big cities in North America, Europe and Latin America shows small changes or a slow growth trend, but the PM2.5 concentration in big cities in Africa and India shows a U-shaped trend, while in China an inverted U-shaped trend. Li et al. [29] analyze China's data and find that overall expansion of cities will significantly increase $\mathrm{CO} 2$ emissions, as smaller cities cannot save land and 
play the externality of industrial agglomeration and bigger cities may produce all kinds of city diseases, so medium-sized cities produce less $\mathrm{CO}_{2}$ than both smaller cities and bigger cities, and medium-sized cities with populations of 1 to 2 million should be given reasonable priority. Dogan et al. [30] argue that economic growth and total energy use are highly $\mathrm{CO}_{2}$ emissions conducive, while urbanization increases environmental degradation at the higher quantiles, as does export quality, depending on the countries' income levels.

(3) Urban-rural income gap and environmental pollution: There are three main views on the impact of income gap on the environment. The first is that the widening income gap is not conducive to environmental pollution control. Torras and Boyce [31] use PSDM model to verify the negative impact of income gap on environmental pollution. Some scholars [32-34] analyze the negative impact of income gap on environmental pollution from the perspective of political stability, sociology, and economics respectively. Masurd et al. [35] analyze data from some Southeast Asian countries and argue that reducing urban-rural income gap is conducive to environmental sustainability. Umut [36] argues that the decline of income inequality will enhance renewable energy consumption and improve environmental quality based on the data from 43 developed and developing countries from 2000 to 2015. Baek and Gweisah [37] point out that income equality can result in better environmental quality in the short- and long -run by analyzing relevant data from the United States. You et al. [38] argue that high levels of inequality, ceteris paribus, in conjunction with poor democratic institutions are likely to result in higher pollution. The second view is that the widening income gap is conducive to improving environmental quality. There is an inverted U-shaped relationship between income inequality and pollution emissions, which means that the development of income gap in a certain stage will improve the environment quality [39-41]. Liu et al. [42] analyze the equilibrium panel data in 31 provinces in China from 1996 to 2015 and argue that the EKC hypothesis of income level and environmental pollution holds water, and income inequality is a key factor to improve environmental quality. Specifically, a $1 \%$ increase in income inequality will be associated with a $0.1819 \%$ decrease in the environmental pollution index. The last view is that the impact of the income gap on the environment is uncertain. By constructing a dynamic model, Vona and Patriarca [43] argue that the relationship between inequality and environmental innovation is highly non-linear and crucially affected by per-capital income, when the local economic development level is high, the widening income gap is not conducive to the demonstration and diffusion of environmental technology, and it is also not conducive to environmental quality improvement. Grunewald et al. [44] argue that the impact of income inequality on the environment depends on the income level of a country's residents.
According to the above literature review, it can be found that in the existing literature, the relationship among city size, urban-rural income gap and environmental pollution is studied rather isolated, and are not put into one same research framework. City size not only affects the urban-rural income gap, but also affects environmental pollution. Therefore, this article combines city size, urban-rural income gap and environmental pollution in the study, trying to figure out the mechanism among these three aspects.

Compared with previous studies, this article may have the following contributions. Firstly, previous research paid more attention to the role of city size on the urban-rural income gap but didn't to consider the counter effect of urban-rural income gap on city size. Hence, this study will fill this gap by studying the effect of urban-rural income gap on city size with China's data. Secondly, this study uses ratio of urban per capita disposable income to rural per capita disposable income to measure the urban-rural income gap, rather than the ratio of urban per capita disposable income to rural per capita net income. China Bureau of statistics adjusted the per capita income index in 2013. To maintain the consistency of data, many related studies only selected the data before 2013 for research. The new indicators used in this paper can make up for this lack of research. Thirdly, this study uses urbanrural income gap as the threshold value, and the Hansen threshold regression method is used to analyze the relationship between city size and environmental pollution, with the threshold value set endogenously by the sample.

\section{Material and Methods}

\section{Research Hypotheses}

City size has two different effects on environmental pollution. One is the scale effect, which is conducive to reducing environmental pollution; the other is the congestion effect, which aggravates environmental pollution. (1) Scale effect. The expansion of city scale is conducive to promoting industrial agglomeration, generating economies of scale, and then reducing environmental pollution. Pollution control has economies of scale which can help reduce the per cost of pollution control. Under the economies of scale, pollution discharge is relatively concentrated, which improves the use efficiency of urban pollution treatment facilities. The scale effect brought by the expansion of city size enables the upstream and downstream enterprises associated with local businesses to gather in space, through which centralization and scale of production can be achieved, thereby improving energy efficiency. (2) Congestion effect. The expansion of city size will accelerate the agglomeration of industry and production activities, producing a congestion effect and increasing pollution emissions. Due to industrial 
agglomeration and concentration of production activities, urban enterprises will increase the demand for energy, which will lead to an increase in energy consumption and emissions of polluted gases and pollutants. Under the congestion effect, problems such as conflicts between man and land, insufficient supply of infrastructure will be prominent. This will further drive cities to occupy green space for infrastructure construction, and lead to a decline in resource utilization efficiency and increase in environmental pollution. Based on the above analysis, we believe that the expansion of the city size will have a dual impact on environmental pollution: in the initial stage of the expansion of city size, the congestion effect will play a major role and increase environmental pollution; while as the city size expands to a certain stage, the scale effect will reduce the regional environment pollution. Therefore, we propose our first hypothesis:

Hypothesis 1: There is an inverted U-shaped relationship between city size and environmental pollution.

Individual residents' income is one of the important factors affecting their preference for environmental quality. (1) The relatively low income level in rural areas makes rural residents care more about individual income and welfare-related benefits with a lower preference for environmental quality as a public good; at the same time, it also leads to more industrial investments with lower levels of environmental requirements in rural areas, which will cause urban pollution industries to move to rural areas, turning rural areas „safe harbors“ for polluting industries. (2) Residents “ environmental awareness is closely related to their income level and education level. Rural residents lack a corresponding understanding of the possible environmental impacts caused by economic activities. Poor environmental awareness is manifested by the lack of awareness and resistance to the damage of environmental pollution. Urban pollutants will be transferred directly or indirectly to rural areas along with pollution industries, which will be rarely dealt with. This will inevitably lead to an increase of more reckless pollution emissions, thus increasing the total pollution. (3) The greater the rights of the rich, the more able they are to transfer environmental costs to the poor, and the more difficult it is for the whole society to reach consensus and cooperation to resolve environmental issues, which will lead to a decline in environmental quality. Based on the above analysis, we propose our second hypothesis:

Hypothesis 2: The urban-rural income gap is positively related to environmental pollution.

The impact of urban size and urban-rural income gap on environmental pollution is not completely independent, and there is often an interaction among them. The reason why city size has different impacts on environmental pollution lies in whether the external effects of cities are mainly scale effects or congestion effects, which is determined by the city size. According to the dual economic theory, a country's economy is divided into industrial and agricultural sectors. Due to the difference in the marginal productivity of labor between urban and rural areas, wages in the industrial sector are higher than in the rural agricultural sector. Income disparity and barrier-free transfers prompt agricultural surplus labor to choose to work in urban industrial sectors, so the large urban-rural income gap in developing countries will cause a steady stream of rural population to migrate to cities. The widening urban-rural income gap attracts rural residents to transfer to the city in large quantities. The transfer of population is often accompanied by the transfer of resources such as capital and labor capacity, which will significantly affect the size of the city and determine its role in environmental pollution. On the one hand, the population continues to agglomerate and increase in a certain city, allowing enterprises and residents to share infrastructure and increase economies of scale. The expansion of city size has certain positive externalities, which is conducive to reducing the negative impact of city size on environmental pollution. On the other hand, when the population size becomes larger and larger, the supply of transportation and infrastructure in the city is insufficient. This will increase urban resource consumption and pollutant emissions, which increases the negative impact of the city size on environmental pollution. Based on the above analysis, we propose our third hypothesis:

Hypothesis 3: The urban-rural income gap has a regulatory effect in the relationship between city size and environmental pollution.

\section{Benchmark Regression Model}

Based on the research hypothesis above, we establish three regression models:

$P I_{i t}=\alpha_{1} P I_{i t-1}+\alpha_{2} P O P+\alpha_{3} P O P^{2}+\alpha_{4} X+\delta_{i}+\mu_{t}+\epsilon_{i t}$

$$
\begin{gathered}
P I_{i t}=\alpha_{1} P I_{i t-1}+\alpha_{2} P O P+\alpha_{3} P O P^{2}+\alpha_{4} X \\
+\alpha_{5} G A P+\delta_{i}+\mu_{t}+\epsilon_{i t} \\
P I_{i t}=\alpha_{1} P I_{i t-1}+\alpha_{2} P O P+\alpha_{3} P O P^{2}+\alpha_{4} X \\
+\alpha_{5} G A P+\alpha_{6} G A P \times P O P+\delta_{i}+\mu_{t}+\epsilon_{i t}
\end{gathered}
$$

Among them, $P I$ is the explained variable and represents the environmental pollution level, $P O P$ is explanatory variable and represents the city size, $P O P^{2}$ is the quadratic term of city size, $X$ is the control variable, and $G A P$ represents the urban-rural income gap. Considering the dynamic characteristics of environmental pollution, a lagging period of environmental pollution is added to each model. 


\section{Sample Selection and Data Source}

According to the principle of data availability and validity, we selected panel data from 283 cities at the level of municipality or above from 2014 to 2017 in China for analysis (data of Lhasa, Karamay, Urumqi, Chaohu, Bijie, and Tongren is missing). According to relevant official data from the China City Statistical Yearbook (2013), there are 289 cities at the prefecture level or above. Cities at the prefecture-level or above are the main production and economic center in each region, and they bear a lot of production responsibilities. More economic activities are carried out in these cities, and the total amount of pollution generated by them also accounts for a large amount of the local area. Therefore, cities at the prefecture level or above are more responsible for the function of regional development. In addition, the 283 cities in this study cover all urban types in China, including large international cities such as Beijing and Shanghai, as well as many small and medium-sized cities. There are not only eastern coastal cities, but also inland cities, traditional resource-based cities and modern serviceoriented cities. Therefore, the selection of 283 cities at the prefecture level or above as research targets is highly representative. The reason why this article selects panel data from 2014 to 2017 is because the National Bureau of Statistics of China has adopted rural per capita disposable income rather than per capita net income to measure the income level of rural residents since 2013. However, some cities did not adopt new indicators for statistics in 2013, and when this research was carried out, there were still some cities that did not publish relevant data for 2018. In summary, we choose 2014-2017 as the sample interval to ensure data consistency and accuracy. The data comes from the China City Statistical Yearbook and China Statistical Yearbook (2015-2018), and some missing data comes from the statistical yearbooks of each city. The main variables are as follows:

(1) Explained variable: Environmental pollution $(P I)$. Wastewater discharge, sulfur dioxide discharge, and smoke (dust) discharge are commonly used indicators for measuring environmental pollution. Based on the research of $\mathrm{Hu}$ and $\mathrm{Li}$ [45], this paper uses the integrated pollution index $(P I)$ as a proxy for environmental pollution, and calculates the comprehensive pollution index based on wastewater discharge, sulfur dioxide emissions, and smoke (dust) emissions. Wastewater, sulfur dioxide, and smoke (dust) are the most common indicators of regional environmental pollution. The statistical bureaus of each cities in China publish these three indicators every year. These three indicators can represent the degree of environmental pollution in a certain area. However, putting these indicators into the regression equation without treatment will bring about two problems: Firstly, since the emissions of different pollutants may be highly correlated, it will produce the collinearity problem when putting them into one equation. Secondly, if these indicators are simply summed up into one variable and then regressed, it will be difficult to compare the measurement of each pollutant horizontally. The specific methods to overcome the above problems are as follows:

$$
P I_{i t}=\frac{P V_{i 1}+P V_{i 2}+P V_{i 3}}{3}, P V_{i j}=P_{i j} / \sum_{i=1}^{n} \frac{P_{i j}}{n}
$$

Among them, $P_{i j}$ represents the discharge amount of pollutant $j(j=1,2,3)$ in area $i$ (n areas in total), and $P V_{i j}$ indicates the pollution environmental index of area $i$ relative to the national average. The larger the value of $P V_{i j}$, the higher the emission level of the first pollutant in city i across the country. Since $P V_{i j}$ itself is a dimensionless variable, it makes sense to perform the total average. In the robustness test, the per capita sulfur dioxide emissions were used as the explained variable to verify the reliability of the results.

(2) Explanatory variable: city size $(P O P)$, it is expressed as the total population (million) at the end of the year under the jurisdiction of the city. GAP represents the urban-rural income gap, which is expressed by the ratio of the per capita disposable annual income of urban residents to the per capita disposable income of rural residents. Among them, the urban residents refer to all the permanent residents living in the urban area, while the rural residents refer to all the population except the above population. Residents' disposable income refers to the sum of the residents ${ }^{6}$ final consumption expenditure and savings. The interpretation and measurement of the above indicators are all from the National Bureau of Statistics of China, and this is consistent with the current studies [46].

(3) Control variables: IS indicates the industrial structure and calculated by the ratio of the output value of the secondary industry to GDP; TE indicates the technological progress and calculated by the ratio of scientific technological inputs to GDP; FDI indicates the level of openness, and it is calculated by the proportion of foreign direct investment that cities actually use each year to the regional GDP; GDP indicates the level of economic development and is expressed in local per capita GDP (ten thousand yuan/person). In addition, considering the relationship between economic growth and the environmental Kuznets curve, the quadratic term of the level of economic development is also added to the control variables, which is represented by $G D P^{2}$.

To eliminate inflation effect, all indicators of monetary value in the control variables are deflated and eliminated based on the GDP deflator of 2013. In addition, to eliminate the dimensional relationship among variables, each variable is standardized before empirical analysis. Table 1 shows the descriptive statistics before the standardization of the main variables. 
Table 1. Descriptive analysis.

\begin{tabular}{|c|c|c|c|c|c|c|}
\hline Variable & $\mathrm{N}$ & Mean & Min & Median & Max & Std \\
\hline$P I$ & 1132 & 0.971 & 0.001 & 0.741 & 13.444 & 1.046 \\
\hline$P O P$ & 1132 & 161.271 & 15.300 & 106.4 & 2449 & 220.238 \\
\hline$G A P$ & 1132 & 2.387 & 1.000 & 2.265 & 37.590 & 1.549 \\
\hline$G D P$ & 1132 & 44288.760 & 1349.305 & 30407.280 & 451022.800 & 4625.320 \\
\hline$F D I$ & 1132 & 0.023 & 0.000 & 0.0138 & 0.775 & 0.044 \\
\hline$T E$ & 1132 & 0.008 & 0.000 & 0.005 & 0.207 & 0.014 \\
\hline$I S$ & 1132 & 0.463 & 0.127 & 0.478 & 0.715 & 0.201 \\
\hline
\end{tabular}

\section{Results and Discussion}

\section{Analysis of Linear Estimation Results}

The data used in this article is panel data of 283 cities from 2014 to 2017, which is a short panel of large $N$ and small $T$. The explanatory variable contains the lag term of the explained variable, although the lag term can be used to study the persistent characteristics of environmental pollution changes, it will inevitably bring about endogenous problems. The estimator using fixed effects or random effects estimation methods for dynamic panel data models must be biased and nonuniform. Generally, the generalized moment estimation (GMM) method proposed by Arellano and Bond (1991) is used [47]. GMM is divided into two methods, one is the difference generalized moment estimation method (Diff-GMM), the other is the system generalized moment estimation (SGMM). The SGMM method combines the differential GMM with the horizontal GMM, and both uses the differential equation and the horizontal equation as an equation system for GMM estimation, which is more efficient than the Diff-GMM. Therefore, this study mainly uses SGMM method for estimation. GMM estimation requires first-order autocorrelation of perturbations, while second-order autocorrelation is not allowed. We use AR to perform serial autocorrelation test and Sargan test to justify the validity of instrumental variables. This article uses the SGMM method for estimation. The estimation results are shown in Table 2. Model 1 is used to test Hypothesis 1, model 2 is used to test Hypothesis 2, and model 3 is used to test Hypothesis 3. The AR (1) and AR (2) test results show that the SGMM estimation is consistent and valid, and the Sargan test results also show that the selection of instrumental variables is reasonable and reliable.

From Table 2, we can see that: (1) The primary coefficient of city size and environmental pollution is significantly positive at the level of $1 \%$, and the secondary coefficient is significantly negative, which indicates that the city size and environmental pollution have an inverted U-shaped relationship. This is consistent with Hypothesis 1. City size influences environmental pollution through the scale effect or congestion effect. At the beginning of the expansion of the city size, due to the large number of people and industries agglomerating to the city, the city lacks a perfect mechanism to solve the environmental

Table 2. Sample estimation results.

\begin{tabular}{|c|c|c|c|}
\hline & Model 1 & Model 2 & Model 3 \\
\hline L.PI & $\begin{array}{c}0.011^{* * *} \\
{[0]}\end{array}$ & $\begin{array}{c}0.018^{* * *} \\
{[0]}\end{array}$ & $\begin{array}{l}0.010^{* * *} \\
{[0.003]}\end{array}$ \\
\hline$P O P$ & $\begin{array}{l}0.172^{* * *} \\
{[0.003]}\end{array}$ & $\begin{array}{l}0.225^{* * *} \\
{[0.005]}\end{array}$ & $\begin{array}{l}0.752^{* * *} \\
{[0.002]}\end{array}$ \\
\hline$P O P^{2}$ & $\begin{array}{c}-0.323^{* * *} \\
{[0.001]}\end{array}$ & $\begin{array}{c}-0.336^{* * *} \\
{[0.003]}\end{array}$ & $\begin{array}{c}-0.262^{* * *} \\
{[0]}\end{array}$ \\
\hline GAP & & $\begin{array}{l}0.840^{* * *} \\
{[0.006]}\end{array}$ & $\begin{array}{l}0.541^{* *} \\
{[0.015]}\end{array}$ \\
\hline$P O P \times G A P$ & & & $\begin{array}{c}-11.486^{* *} \\
{[0.010]}\end{array}$ \\
\hline$G D P$ & $\begin{array}{l}0.355^{* *} \\
{[0.014]}\end{array}$ & $\begin{array}{l}0.443^{* *} \\
{[0.043]}\end{array}$ & $\begin{array}{c}0.447^{*} \\
{[0.061]}\end{array}$ \\
\hline$G D P^{2}$ & $\begin{array}{l}-0.475^{*} \\
{[0.069]}\end{array}$ & $\begin{array}{l}-0.606^{*} \\
{[0.084]}\end{array}$ & $\begin{array}{l}-0.559^{*} \\
{[0.061]}\end{array}$ \\
\hline IS & $\begin{array}{l}0.034^{* *} \\
{[0.016]}\end{array}$ & $\begin{array}{l}0.016^{* *} \\
{[0.011]}\end{array}$ & $\begin{array}{l}0.009^{* *} \\
{[0.017]}\end{array}$ \\
\hline$T E$ & $\begin{array}{l}-0.169^{* *} \\
{[0.015]}\end{array}$ & $\begin{array}{c}-0.140^{* *} \\
{[0.017]}\end{array}$ & $\begin{array}{l}-0.150^{* *} \\
{[0.043]}\end{array}$ \\
\hline$F D I$ & $\begin{array}{c}-0.035^{* * *} \\
{[0.005]}\end{array}$ & $\begin{array}{l}0.367^{* * *} \\
{[0.001]}\end{array}$ & $\begin{array}{l}0.415^{* * *} \\
{[0.003]}\end{array}$ \\
\hline $\mathrm{C}$ & $\begin{array}{l}2.914^{* *} \\
{[0.026]}\end{array}$ & $\begin{array}{l}-0.692^{* *} \\
{[0.033]}\end{array}$ & $\begin{array}{l}-0.573^{* *} \\
{[0.041]}\end{array}$ \\
\hline $\operatorname{AR}(1)$ & 0.007 & 0.006 & 0.010 \\
\hline $\operatorname{AR}(2)$ & 0.541 & 0.492 & 0.523 \\
\hline Sargan & 0.600 & 0.513 & 0.512 \\
\hline Time effect & YES & YES & YES \\
\hline $\begin{array}{l}\text { Regional } \\
\text { effect }\end{array}$ & YES & YES & YES \\
\hline
\end{tabular}

Notes: $\mathrm{p}$ values are in brackets, ${ }^{*},{ }^{* *}$ and

${ }^{* * *}$ represent significance at $10 \%, 5 \%$ and $1 \%$ levels; values of AR and Sargan tests are p values. 
pollution caused by the scale effect. With the expansion of the city size, the consumption structure tends to be environmentally friendly, and the industrial structure becomes more advanced. The existence of scale effect greatly reduces the average cost of environmental governance and improves regional environmental quality to a certain extent. (2) The coefficient between urban-rural income gap and environmental pollution is significantly positive, which is consistent with Hypothesis 2. The widening urban-rural income gap has made a big difference between rural and urban environmental governance. The standards of environmental planning are relatively higher in cities than that in rural areas. This differentiated pattern causes the urban pollution brought by urban economic activities and urban residents' lives to inevitably exceed the pollution emissions corresponding to their planned levels. These excess emissions will be continuously transferred to the rural areas, resulting in increased emissions and pollution. (3) The cross-term coefficient of city size and environmental pollution is significantly negative, which is consistent with Hypothesis 3. Urban-rural income gap has a regulatory effect on the relationship between city size and environmental pollution. Expansion of the city size will widen the urban-rural income gap, while the urban-rural income gap will also affect the city size, limiting or enhancing their role on environmental pollution. Scale is not the only factor that affects urban development. Diversified urban systems and the characteristics of each city are also other important factors that affect urban development. Therefore, we cannot expect the optimal city size to be the same or even exist for all cities. However, many scholars' studies have shown that economies of scale, increased returns to scale, and externalities are related to city size [48]. When the urban-rural income gap is relatively small, cities are less attractive to rural residents, and rural residents are less willing to migrate to the city. The expansion of city scale at this stage has scale effect, which has positive externalities and is conducive to reducing the negative impact of city size on environmental pollution. However, a large urban-rural income gap will prompt more rural residents to move to cities. When the urban population exceeds the reasonable carrying capacity, this will exacerbate congestion effect and increase environmental pollution. Therefore, the urban-rural income gap will affect the city size and regulate its effect on environmental pollution.

For the other variables: (1) the regression coefficient of the first-order lag of environmental pollution is significantly positive, indicating that there is a significant dynamic effect of environmental pollution. (2) The coefficient of the first term of the economic development is significantly positive and the coefficient of the second term is significantly negative, which means there is an EKC between the level of economic development and environmental pollution. In the early stage of economic development, residents and enterprises paid more attention to the improvement of income levels and ignored environmental quality. When the economy develops to a certain level, with the improvement of industrial structure, technological progress and environmental awareness, environmental quality will gradually improve. (3) The regression coefficient of industrial structure and environmental pollution is positive at the significance of $5 \%$ level, which indicates that the higher the proportion of the secondary industry, the more serious the environmental pollution. Most of the secondary industry is characterized by high pollution and high energy consumption, such as mining, manufacturing, electricity, gas, and construction, which is in line with China's actual situation. (4) The regression coefficient of technological progress and environmental pollution is significantly negative. Technological progress can optimize the industrial structure, improve pollution control, and significantly reduce environmental pollution. (5) The coefficient of the degree of opening to the outside world is significantly negative, which proves Pollution Haven Hypothesis is invalid. FDI may bring spillover effect on the clean technology of upstream and downstream industries by introducing environmentally friendly products, which is beneficial to the improvement of regional environmental quality.

\section{Analysis of Threshold Regression Results}

To further investigate the impact of the urban-rural income gap on the relationship between city size and environmental pollution, this paper expands the linear model to a non-linear model and adopts the threshold regression method proposed by Hansen (1999) [49]. We use the urban-rural income gap as the threshold variable to demonstrate the impact of city size on environmental pollution. In this way, the artificial factors of grouping can be overcome, and Hansen threshold model can find the threshold value through repeated sampling of samples. Therefore, we build the following regression model:

$$
\begin{gathered}
P I_{\mathrm{it}}=\theta_{1} P O P_{i t} I\left(G A P \leq \gamma_{1}\right)+\theta_{2} P O P_{i t} I\left(\gamma_{1}<G A P \leq \gamma_{2}\right) \\
+\cdots+\theta_{n} P O P_{i t} I\left(G A P>\gamma_{n}\right)+\beta_{1} G A P_{i t}+\beta_{2} X \\
+\delta_{i}+\mu_{t}+\epsilon_{i t}
\end{gathered}
$$

Among them, I( $\cdot)$ is the index function, when the corresponding condition is established, the value is 1 , otherwise it is $0 ; G A P$ is the threshold variable and represents urban-rural income gap; $P I$ is the environmental pollution; $P O P$ is the city size; $X$ is the control variable, which is the same as the control variable selected above; the model also controls time effect and regional effect. This paper uses Stata14.0 software for threshold effect test. Firstly, it is necessary to test whether there is a threshold, and if it exists, then it is necessary to further estimate the threshold level. 
Table 3. Threshold model self-sampling test.

\begin{tabular}{|c|c|c|c|c|c|c|}
\hline \multirow{2}{*}{ Threshold } & \multirow{2}{*}{$\mathrm{F}$} & $\mathrm{j}$ & \multirow{2}{*}{$\begin{array}{c}\text { Bootstrap } \\
\text { numbers }\end{array}$} & \multicolumn{4}{|c|}{ Critical value } \\
\cline { 5 - 8 } & & & $1 \%$ & $5 \%$ & $10 \%$ \\
\hline Single threshold & $36.356^{* * *}$ & 0.004 & 500 & 43.653 & 34.153 & 23.742 \\
\hline Double threshold & 7.340 & 0.169 & 500 & 12.496 & 12.203 & 9.735 \\
\hline
\end{tabular}

Notes: ${ }^{*},{ }^{* *}$ and ${ }^{* * *}$ represent significance at $10 \%, 5 \%$ and $1 \%$ levels.

Table 4. Threshold estimates and confidence intervals.

\begin{tabular}{|c|c|c|}
\hline & Threshold estimate & $\begin{array}{c}95 \% \text { confidence } \\
\text { interval }\end{array}$ \\
\hline $\begin{array}{c}\text { Single threshold } \\
\text { model }(G A P)\end{array}$ & 0.164 & $(0.158,0.169)$ \\
\hline
\end{tabular}

Secondly, this study uses the likelihood ratio (LR) to test whether the threshold value is equal to the real value. In this study, 200 network search points are set up and 500 bootstrap repetitions are performed. The threshold search results are showed in Tables 3 and Table 4.

The results are showed in Tables 3 and Table 4, we can see that: in the single threshold test, there is a threshold value of 0.164; while in the double threshold test, the $\mathrm{F}$ value and $\mathrm{p}$ value do not pass the significance test, so there is no double threshold. Based on this, a single threshold model is used for

Table 5. Threshold model estimation results.

\begin{tabular}{|c|c|c|}
\hline & $P I$ & $P I^{*}$ \\
\hline $\begin{array}{c}P O P 1 \\
\left(G A P \leq \gamma_{1}\right)\end{array}$ & $\begin{array}{l}0.009^{* * *} \\
{[0.004]}\end{array}$ & $\begin{array}{l}0.006^{* *} \\
{[0.012]}\end{array}$ \\
\hline $\begin{array}{c}P O P^{2} \\
\left(G A P>\gamma_{1}\right)\end{array}$ & $\begin{array}{l}0.112^{* * *} \\
{[0.001]}\end{array}$ & $\begin{array}{l}0.113^{* *} \\
{[0.041]}\end{array}$ \\
\hline$G A P$ & $\begin{array}{l}0.007^{* *} \\
{[0.010]}\end{array}$ & $\begin{array}{l}0.023^{* *} \\
{[0.015]}\end{array}$ \\
\hline$G D P$ & $\begin{array}{l}-0.054^{* *} \\
{[0.025]}\end{array}$ & $\begin{array}{l}-0.035^{* *} \\
{[0.030]}\end{array}$ \\
\hline$G D P^{2}$ & $\begin{array}{l}0.191^{* *} \\
{[0.021]}\end{array}$ & $\begin{array}{c}0.153^{*} \\
{[0.052]}\end{array}$ \\
\hline$I S$ & $\begin{array}{l}0.032^{* *} \\
{[0.019]}\end{array}$ & $\begin{array}{c}0.048^{*} \\
{[0.072]}\end{array}$ \\
\hline$T E$ & $\begin{array}{l}-0.013^{*} \\
{[0.069]}\end{array}$ & $\begin{array}{c}-0.039 \\
{[0.106]}\end{array}$ \\
\hline$F D I$ & $\begin{array}{c}-0.001^{* * *} \\
{[0.006]}\end{array}$ & $\begin{array}{c}-0.035^{* * *} \\
{[0.009]}\end{array}$ \\
\hline $\mathrm{C}$ & $\begin{array}{l}7.671^{* *} \\
{[0.031]}\end{array}$ & $\begin{array}{c}4.353^{*} \\
{[0.069]}\end{array}$ \\
\hline Time effect & YES & YES \\
\hline Regional effect & YES & YES \\
\hline
\end{tabular}

Notes: $\mathrm{p}$ values are in brackets, ${ }^{*},{ }^{* *}$ and

${ }^{* * *}$ represent significance at $10 \%, 5 \%$ and $1 \%$ levels. empirical analysis. Table 5 shows the estimation results of the threshold regression model. The first column uses $P I$ as the explained variable. In addition, $P I^{*}$ is used as the explained variable for a robustness test, which is calculated by per capita sulfur dioxide emissions. After testing, GAP also has one single threshold of 0.160 , which is estimated by using formula 5. The specific results are shown in the second column of Table 5 .

According to the estimation results in Table 5, the urban-rural income gap threshold divides the city size level into Class I $(G A P \leq 0.164)$ and Class II $(G A P>0.164)$. The effect of city size on environmental pollution is not the same in each interval. When $G A P \leq 0.164$, the coefficient of city size and environmental pollution is 0.009 , which is significant at the level of $1 \%$; when $G A P>0.164$, the coefficient of city size and environmental pollution is 0.112 , which is significant at the level of $1 \%$. The wider urban-rural income gap is, the stronger the negative impact of city size on environmental pollution is. The possible explanation behind this conclusion is that when urban-rural income gap is small, there is no significant difference in income between rural residents and urban residents. Population, enterprises and other resources are less concentrated in the city, and the congestion effect of the city size is not obvious. But when the urban-rural income gap widens to a certain degree, the large urban-rural income gap has a huge appeal to rural residents, prompting them to move to cities in large numbers. As a result, the congestion effect of the city size is prominent, and urban environmental pollution has increased. The second column of Table 5 shows the threshold regression results of $P I^{*}$ as the explanatory variable, which is consistent with the foregoing conclusions. The widening urban-rural income gap exacerbates the negative impact of city size on environmental pollution, which indicates that the conclusions of this study are robust. In addition, the regression coefficients of each control variable are basically consistent with the foregoing analysis.

\section{Conclusions}

For China and other developing countries, the widening urban-rural income gap and increasing environmental pollution have become the most serious 
problems in the process of city expansion. It is of practical significance to study the relationship among city size, urban-rural income gap and environmental pollution. This paper analyzes China's city-level panel data from 2014 to 2017 to conduct an empirical test on the relationship among these three. The results show that, after controlling factors such as economic development level, industrial structure, technological progress, and openness to the outside world, the city size and environmental pollution present an inverted U-shaped relationship; the urban-rural income gap has a significantly positive impact on environmental pollution. Using Hansen threshold model and taking the urbanrural income gap as the threshold variable, it is further found that when the urban-rural income gap is too large, the negative impact of city size on environmental pollution increases strongly, and the urban-rural income gap has a significant regulatory effect on the impact of city size and environmental pollution.

The implications of this study are as follows:

(1) Treating the relationship between city size and environmental pollution in a dynamically view. The optimal city size has always been a hot issue that is widely concerned by all sectors of society and academia. The relationship between city size and environmental pollution should be dealt with objectively. For the early stage of city development, due to the lack of a perfect city management mechanism, the concentration of population and enterprises in the city can easily lead to congestion effects and aggravate environmental pollution. A comprehensive plan for city development should be formulated to optimize coordination at the beginning of city expansion. For the later stage of city development, the problem of „urban disease“ may arise. Urban resources should be coordinated to exert its scale effect and reduce the cost of environmental governance by optimizing urban layout and centralized treatment of pollution etc.

(2) Narrowing the urban-rural income gap. Excessive urban-rural income gap not only directly aggravates environmental pollution, but also further exacerbates it by promoting the transfer of rural residents to cities which leads to the congestion effect of city size. Therefore, it is necessary to reduce environmental pollution while narrowing the income gap, to solve the problem of income inequality during development, and to avoid or reduce the pollution pressure caused by the widening income gap. To control pollution, the management should take into consideration the overall situation, paying attention to the internal logic and influence mechanism between income gap and environmental pollution, and take effective measures to narrow urban-rural income gap instead of relying solely on environmental protection departments.

(3) To solve the problem of environmental pollution caused by the expansion of city size, other measures can also be taken. Improving the level of local economic development and accelerating the inflection point of the EKC curve; optimizing the industrial structure and reducing the secondary industry proportion; increasing investment in technology and optimizing the structure of foreign investment.

In addition, this article only selected the data from 2014 to 2017 as the research object to ensure the consistency and accuracy of the article data. Although we have obtained data from 283 prefecture-level and above cities in China, but the sample period selected in this article is relatively short. With the enrichment of sample data in the future, scholars can use more samples to confirm the research conclusions. There are many types of research on environmental pollution caused by the expansion of city size, but the conclusions are different. It may be that other factors have influenced their conclusions. In the future, scholars can also try to add more variables to study the relationship between them.

\section{Acknowledgements}

The authors gratefully acknowledge the financial support provided by the National Natural Science Foundation of China, China, grant number 71673270; The Think Tank of Energy Mining Economy (2018 Project for Cultural Evolution and Creation of CUMT, China), grant number 2018WHCC01.

\section{Conflict of Interest}

The authors declare no conflict of interest.

\section{References}

1. ALPEROVICH G. The relationship between income inequality and city size: a general equilibrium model of an open system of cities approach. Urban Studies, 32 (6), 853, 1995.

2. DAVID C. Beyond Kuznets: inequality and the size and distribution of cities. Journal of Regional Science, 58 (3), 564, 2018.

3. WANG X., SHAO S., LI L. Agricultural inputs, urbanization, and urban-rural income disparity: evidence from China. China Economic Review, 55, 67, 2019.

4. BAEK J., GWEISAH G. Does income inequality harm the environment? Empirical evidence from the United States. Energy Policy, 62, 1434, 2013.

5. LU M., CHE Z. Urbanization, urban-biased policies, and urban-rural inequality in China, 1987-2001. Chinese Economy, 39 (3), 42, 2006

6. LU Y., WANG F. From general discrimination to segmented inequality: migration and inequality in urban China. Social Science Research 42 (6), 1443, 2016.

7. PARK A., WANG D. Migration and urban poverty and inequality in China. China Economic Journal 3 (1), 49, 2010.

8. ZHANG K.H., SONG S. Rural-urban migration and urbanization in China. China Economic Review 14, 386, 2014. 
9. PAN L., MUKHOPADHAYA P., LI J. City size and wage disparity in segmented labour market in China. Australian Economic Papers 55 (2), 128, 2016.

10. CHEN B.K., LIU D., LU M. City size, migration and urban inequality in China. China Economic Review 51, 42, 2018.

11. LI L., LEI Y.L., WU S.M., HE C.Y., CHEN J.B., YAN D. Optimal scale of China's cities under the maximization of economic benefits and environmental benefits. Environmental Science and Pollution Research 24, 19946, 2017.

12. YUAN M., HUANG Y.P., SHEN H.F., LI T.W. Effects of urban form on haze pollution in China: spatial regression analysis based on PM2.5 remote sensing data. Applied Geography, 98, 215, 2018.

13. JIANG P., YANG J., HUANG C., HUANG C.H., LIU H.K. The contribution of socioeconomic factors to PM 2.5, pollution in urban China. Environmental Pollution 233, 977, 2018.

14. YUAN M., SONG Y., HUANG Y.P., HONG S.J., HUANG L.J. Exploring the association between urban form and air quality in China. Journal of Planning Education and Research, 38 (4), 413, 2018.

15. BEREITSCHAFT B., DEBBAGE K. Urban form, air pollution, and $\mathrm{CO}_{2}$ emissions in large US metropolitan areas. Professional Geographer, 65 (4), 612, 2013.

16. BROWN M.A., SOUTHWORTH F. Mitigating climate change through green buildings and smart growth. Environment \& Plan A 40 (3), 653, 2008.

17. SATTERTHWAITE D. Environmental transformations in cities as they get larger, wealthier and better managed. Geographical Journal 163 (2), 216, 1997

18. LIU Q.Q., WANG S.J., ZHANG W.Z., LI J.M. Income distribution and environmental quality in China: a spatial econometric perspective. Journal of Cleaner Production, 205 (20), 14, 2018.

19. LIAO S.M., WANG D., LIANG Z.J., XIA C.Y., GUO H., ZHAO W.J. Spatial spillover effect and sources of citylevel haze pollution in China: A case study of Guangdong provinces. Polish Journal of Environmental Studies, 29 (5), 3213, 2020.

20. 2BORCK R., TABUCHI T. Pollution and city size: can cities be too small? Journal of Economic Geography, 19 (5), 995, 2019.

21. WANG Y.Z., HANG Y., WANG Q.W., ZHOU D.Q., SU B. Cleaner production vs end-of-pipe treatment: Evidence from industrial $\mathrm{SO} 2$ emissions abatement in China. Journal of Environmental Management, 277, 111429, 2021.

22. WANG F., WANG G., LIU J., CHEN H.T. How does urbanization affect carbon emission intensity under a hierarchical nesting structure? Empirical research on the China Yangtze River Delta urban agglomeration. Environmental Science and Pollution Research, 26 (31), 31770, 2019.

23. MULLER N.Z., JHA A. Does environmental policy affect scaling laws between population and pollution? Evidence from American metropolitan areas. PLoS One, 12 (8), e0181407, 2017.

24. MIAO Z., CHEN X.D., BALEZENTIS T., SUN C.W. Atmospheric environmental productivity across the provinces of China: Joint decomposition of range adjusted measure and Luenberger productivity indicator. Energy Policy, 132, 665, 2019.

25. HANG Y., WANG Q.W., WANG Y.Z., SU B., ZHOU D.Q. Industrial $\mathrm{SO} 2$ emissions treatment in China: A temporal- spatial whole process decomposition analysis. Journal of Environmental Management, 243, 419, 2019.

26. SUN Z.Q., SUN T. The impact of multi-dimensional urbanization on China's carbon emissions based on the spatial spillover effect. Polish Journal of Environmental Studies, 29 (5), 3317, 2020.

27. SHI K.F., WANG H., YANG Q.Y., WANG L., SUN X.F., LI Y.Q. Exploring the relationships between urban forms and fine particulate (PM2.5) concentration in China: A multi-perspective study. Journal of Cleaner Production, 231, 990, 2019.

28. LIU S., FAN F., ZHANG J.Q. Are small cities more environmentally friendly? An empirical study from China. International Journal of Environmental Research \& Public Health, 16 (5), 727, 2019.

29. LI L., LEI Y.L., WU S.M., HE C.Y., CHEN J.B., YAN D. Impacts of city size change and industrial structure change on $\mathrm{CO}_{2}$ emissions in Chinese cities. Journal of Cleaner Production, 195 (10), 831, 2019.

30. DOGAN B., MADALENO M., TIWARI A.K., HAMMOUDEH S. Impacts of export quality on environmental degradation: does income matter?. Environmental Science and Pollution Research, 27 (12), 13735, 2020.

31. TORRAS M., BOYCE J.K. Income, inequality, and pollution: A reassessment of the environmental Kuznets curve. Ecological Economics, 25 (2), 147, 1998.

32. COONDOO D., DINDA S. Carbon dioxide emission and income: a temporal analysis of cross-country distributional patterns. Ecological Economics, 65 (3), 375, 2008.

33. HIDEFUMI K., MASAKI T. Does inequality affect environmental quality? Evidence from major Japanese cities. Journal of Cleaner Production, 142, 3689, 2017.

34. PADHAN H., HAOUAS I., SAHOO B., HESHMATI A. What matters for environmental quality in the next11 countries: economic growth or income inequality? Environmental Science and Pollution Research, 26 (22), 23129, 2019.

35. MASURD M.M., KARI F.B., BANNA H., SAIFULLAH M. Does income inequality affect environmental sustainability? Evidence from the ASEAN-5. Journal of Asia Pacific Economy, 23 (2), 1, 2018.

36. UMUT U. Is income inequality a driver for renewable energy consumption? Journal of Cleaner Production, 255, 120287, 2020

37. BAEK J., GWEISAH G. Does income inequality harm the environment? Empirical evidence from the United States. Energy Policy, 62, 1434, 2013.

38. YOU W., LI Y.H., GUO P., GUO Y.W. Income inequality and $\mathrm{CO}_{2}$ emissions in belt and road initiative countries: the role of democracy. Environmental Science and Pollution Research, 27, 6278, 2020.

39. RIDZUAN S. Inequality and the environmental Kuznets curve. Journal of Cleaner Production, 228, 1472, 2019.

40. HEERINK N., MULATU A., BULTE E. Income inequality and the environment: aggregation bias in environmental Kuznets curves. Ecological Economics, 38 (3), 359, 2001.

41. BRANNLUND R., GHALWASH T. The income-pollution relationship and the role of income distribution: an analysis of Swedish household data. Resource \& Energy Economics, 30 (3), 369, 2008.

42. LIU Q.Q., WANG S.J., ZHANG W.Z., LI J.M. Income distribution and environmental quality in China: a spatial econometric perspective. Journal of Cleaner Production, 205 (20), 14, 2018. 
43. VONA F., PATRIARCA F. Income inequality and the development of environmental technologies. Ecological Economics, 70 (11), 2201, 2011.

44. GRUNEWALD N., KLASEN S., MARTINEZ-ZARZOSO I., MURIS C. The trade-off between income inequality and carbon dioxide emissions. Ecological Economics, 142, 249, 2017.

45. HU Z.Y., LI Y. Dual effects and threshold characteristics of financial development on environmental pollution. China Soft Science, 7, 68, 2019.

46. LU M., CHEN Z. Urbanization, urban-biased economic policies and urban-rural inequality. Economic Research Journal, 6, 50, 2004.
47. ARELLANO M., BOND S. Some tests of specification for panel data: Monte Carlo evidence and an application to employment equations. Review of Economics Studies, $\mathbf{5 8}$ (2), 277, 1991.

48. YANG Z. Development of optimal city size theory: A critical view. Journal of Resources \& Ecology, 11 (1), 100, 2020.

49. HANSEN B.E. Threshold effects in non-dynamic panels: Estimation, testing, and inference. Journal of Econometrics, 93 (2), 345, 1999. 